IZA DP No. 4761

The ART of Life: IVF or Child Adoption?

Gulcin Gumus

Jungmin Lee

February 2010 


\title{
The ART of Life: IVF or Child Adoption?
}

\author{
Gulcin Gumus \\ Florida International University \\ and IZA \\ Jungmin Lee \\ Florida International University \\ and IZA
}

\section{Discussion Paper No. 4761 \\ February 2010}

\author{
IZA \\ P.O. Box 7240 \\ 53072 Bonn \\ Germany \\ Phone: +49-228-3894-0 \\ Fax: +49-228-3894-180 \\ E-mail: iza@iza.org
}

Any opinions expressed here are those of the author(s) and not those of IZA. Research published in this series may include views on policy, but the institute itself takes no institutional policy positions.

The Institute for the Study of Labor (IZA) in Bonn is a local and virtual international research center and a place of communication between science, politics and business. IZA is an independent nonprofit organization supported by Deutsche Post Foundation. The center is associated with the University of Bonn and offers a stimulating research environment through its international network, workshops and conferences, data service, project support, research visits and doctoral program. IZA engages in (i) original and internationally competitive research in all fields of labor economics, (ii) development of policy concepts, and (iii) dissemination of research results and concepts to the interested public.

IZA Discussion Papers often represent preliminary work and are circulated to encourage discussion. Citation of such a paper should account for its provisional character. A revised version may be available directly from the author. 
IZA Discussion Paper No. 4761

February 2010

\section{ABSTRACT}

\section{The ART of Life: IVF or Child Adoption?*}

This paper analyzes the effects of child adoption on the utilization of assisted reproductive technology (ART) in the US. Using state-level longitudinal data for 1999-2006, we show that ART use is responsive to changes in adoption markets. Controlling for state-specific fixed effects, the estimated elasticity of ART cycles performed with respect to child adoptions is about -0.13 to -0.15 . The responsiveness is higher when we consider infant adoptions, adoptions by older women, and international adoptions while there is no substitutability between ART and adoption of related children. Our findings suggest that public policies regarding adoption, including subsidies, influence ART use.

JEL Classification: $\quad \mathrm{I} 11, \mathrm{~J} 13, \mathrm{~J} 18$

Keywords: child adoption, infertility treatment, assisted reproductive technology (ART), in vitro fertilization (IVF)

Corresponding author:

Gulcin Gumus

Department of Economics

Florida International University

HLS 554A

11200 SW 8th St.

Miami, FL 33199

USA

E-mail: gumusg@fiu.edu

\footnotetext{
* Part of the data used here were made available by the National Data Archive on Child Abuse and Neglect (NDACAN), Cornell University, Ithaca, NY, and have been used with permission. Data from the Adoption and Foster Care Analysis and Reporting System (AFCARS) were originally collected by the Childrens Bureau. Funding for the AFCARS project was provided by the Children's Bureau, Administration on Children, Youth and Families, Administration for Children and Families, US Department of Health and Human Services. The collector of the original data, the funder, the Archive, Cornell University and their agents or employees bear no responsibility for the analyses or interpretations presented here. We gratefully acknowledge the staff at NDACAN, in particular Michael Dineen, for their assistance. We thank Mary E. Hansen for providing us with the data on adoption assistance rates as well as for her suggestions. We also thank the conference participants at the 2009 Latin American Meetings of the Econometric Society and 2010 Annual Meeting of the American Economic Association for helpful comments. We are grateful to Marianne P. Bitler, Luca Bossi, Kasey Buckles, Carlos A. Flores, Lisa A. Gennetian, Chiaki Moriguchi, Tracy L. Regan, Anna Sanz-deGaldeano, Elizabeth Peters, and Justin Wolfers for their constructive feedback and to Jennifer R. Nimmo for research assistance.
} 


\section{Introduction}

Infertility is recognized as a medical condition and is defined as the inability to conceive after one year of unprotected intercourse. In the US, infertility is a growing problem: over the last several decades, age-related infertility has become increasingly prevalent as a relatively larger portion of women have deferred childbearing due to effective birth control methods, safe and legal abortions, better access to college education, and greater participation in the labor market (Kane and Staiger, 1996; Angrist and Evans, 1999; Caucutt et al., 2002; Goldin and Katz, 2002; Buckles, 2008).

For individuals with fertility problems who want to have children, there are two main alternatives: adoption and infertility treatment. ${ }^{1}$ Chandra et al. (2005) use data from the 2002 National Survey of Family Growth (NSFG) and show that about 57 percent of women who received infertility treatment also considered or actively sought to adopt a child. Infertility is an important factor in determining the demand for adoption. Married childless couples are more likely to seek adoption, and adoption is more prevalent among women who have used infertility services (Chandra et al., 2005; Bernal et al., 2008). Our calculations using the 2002 NSFG show that about 33 percent of the women who are currently seeking to adopt have also sought medical assistance with getting pregnant. The extent to which individuals view child adoption and infertility treatment as alternatives is an empirical question with important economic, social, and public health implications. The answer would indicate whether federal and state adoption policies can significantly influence the decision to pursue assisted reproductive technology $(\mathrm{ART})$.

The motivation for this paper is the recent trend of increasing ART utilization. Since the beginning of the 1980s, diagnostic and treatment options for infertility have advanced dramatically in terms of effectiveness as well as availability. ART now includes several different options which consist of clinical treatment and laboratory procedures such as in vitro fertilization (IVF), gamete intra-fallopian transfer (GIFT), zygote intra-fallopian transfer (ZIFT), embryo cryopreservation, oocyte or embryo donation, and gestational surrogacy. As a result, Americans have been utilizing more and more ART, mostly in the form of IVF. In 1995, an es-

\footnotetext{
${ }^{1}$ Another option is surrogacy if there are no problems with male fertility. This method requires a fertile surrogate mother to be artificially inseminated with sperm who then carries the baby to term. In most states, there are no laws regarding surrogacy arrangements and in others surrogacy agreements are prohibited altogether. Moreover, this is an expensive method as the average cost is estimated to range between $\$ 70,000$ and $\$ 130,000$ in 2009 (Cohen, 2009). This figure is considerably higher than the cost associated with the other two alternatives discussed here.
} 
timated 6.7 million women had impaired fecundity of which 42 percent had received some form of infertility services (Stephen and Chandra, 2000). In 2002, an estimated 7.3 million women had fecundity problems and about 45 percent had received some form of medical assistance (Chandra et al., 2005). The most commonly used infertility services are the non-invasive methods including medical advice, infertility testing, and ovulation drugs. ART, including IVF, is utilized by less than one percent of women, but the number of children conceived through ART is quite high. The Centers for Disease Control and Prevention (CDC) reports indicate that in 1996, 20,840 babies were conceived using ART; this figure more than doubled by 2006 when it soared to 54,656 (CDC, 2008).

The number of adoptions, on the other hand, remained relatively flat during the same period. Recently, Bernal et al. (2008) provide descriptive evidence suggesting that the advancements in ART may be linked to reductions in the demand for domestic infants. They calculate the ratio of the number of women who delivered their own biological children with ART to the number of women who adopted unrelated children domestically and show that this ratio has continuously increased: it was 15 percent in 1992, 34 percent in 1996, and 60 percent in 2002. According to the US Children's Bureau, about 51,000 children were adopted in 2006. However, every year thousands of more children wait to be adopted in the US. The estimated number of children in foster care waiting to be adopted was about 129,000 in 2006 (US DHHS, 2008). The discrepancy between the number of children waiting to be adopted and the number actually adopted is because the adoptive matching of parents and children requires considerable time and resources, and because the demand for adoption remains insufficient (Hansen and Hansen, 2006). A shortage of adoptive parents is a social concern since childhood at foster care is associated with poor lifetime outcomes (see, for example, Doyle, 2007).

Despite the technological advances, ART remains a risky, complex, and expensive endeavor. Such infertility treatments are costly both in terms of money and time. The total cost of a successful delivery using IVF ranged between $\$ 44,000$ and $\$ 211,940$ in 1992 (Neumann et al., 1994) and the average cost was estimated to be more than $\$ 50,000$ in 2001 (Collins, 2001). ART may also have significant adverse health effects on both the mothers and babies, especially as a result of the increased prevalence of multiple gestations. In particular, triplet and higher order multiple pregnancies lead to a greater chance of complications such as prematurity and maternal morbidity (Van Voorhis, 2007). Between 1980 and 1997, the number of annual live born babies from twin gestation rose by 52 percent, while the number of high- 
order multiple gestations increased by 404 percent - these growth rates are mostly attributed to ART (NCHS, 1999). Bitler (2008) estimates that the additional hospital costs associated with a national mandate covering infertility treatment would be $\$ 334$ million in 2000 dollars, due to the expected increase in the number of twin births alone.

The utilization of ART lends itself to controversies over who should have access to such technologies, who should pay for the treatments, and whether the practices and providers should be regulated. Most recently, a mother in California (who already had six young children conceived through IVF) gave birth to octuplets with the help of IVF. This incident sparked a discussion on the ethics of ART and whether there should be regulations on how ART is practiced (Archibold, 2009). Bioethicists who argue in favor of such rules point out that child adoption and foster care are more strictly regulated compared to infertility treatment (Caplan, 2009). Child adoption, as an alternative to ART, has been discussed in similar debates when several states, starting in the late 1980s, have enacted health insurance mandates that regulate coverage for infertility treatment. Currently, 15 states require health insurance plans to provide some form of coverage for infertility treatment. As pointed out earlier by Neumann (1997), any policy decision regarding ART has potential implications for child adoption.

A policy relevant question, which we focus on here, is whether legislative changes regarding the adoption of domestic children from foster care might encourage individuals to choose adoption over ART. Although some individuals might consider adoption as a primary means to having children, many others might pursue adoption only if they fail to conceive a child biologically connected to themselves. Even then, changes in the cost of adoption might influence individuals' decision regarding how the number of ART cycles to use before they give up on this option. In general, the point we make in this paper is that these two markets may be related to one another. In fact, one might expect that there is a stronger link between ART markets and private adoptions. We focus on foster care adoptions since the use of public policy tools is a lot more common for encouraging adoptions from foster care.

To answer our question, we use multiple sources of data on child adoption and ART utilization to construct state-level panel data from 1999 to 2006. Our empirical results indicate changes in adoption markets significantly affect ART utilization. The estimates reveal that a 10 percent increase in child adoptions per 1,000 women would lead to a 1.3 to 1.5 percent decrease in the number of ART cycles performed per 1,000 women. In our models, we control for state-specific fixed effects (FE) and also address the potential simultaneity bias by using an 
instrumental variables estimation method (FE-2SLS). We also carry out additional analyses according to the age of the adopted children and of the adoptive mothers and find that the substitutability is greater for women aged 35 and older as well as for adoptions of younger children. Finally, we perform a series of robustness checks. For example, we provide evidence that the responsiveness is much larger when we consider international adoptions, suggesting that use of ART is more sensitive to the demand for private adoption. On the other hand, there does not seem to be a relationship between ART markets and adoptions of related children from foster care.

The rest of the paper is organized as follows: section 2 provides a review of the previous literature and section 3 describes the data used in the analysis. Section 4 outlines the empirical framework and presents the results. Section 5 concludes.

\section{$2 \quad$ Literature Review}

\subsection{Literature on Child Adoption}

Adoption seems less risky than pursuing ART since individuals typically end up with a child at the end of the process. In addition, most of the costs of adoption are incurred at the end, only when the actual adoption process has taken place (Neumann, 1997). Still, child adoption is a fairly complex, time-consuming, and uncertain process. The cost of child adoption, beyond the document preparation and legal fees, varies widely depending on the type of adoption. The US Children's Bureau reports that foster care adoption costs can be as much as $\$ 2,500$, domestic infant adoption costs vary between $\$ 5,000$ and $\$ 40,000$, and international adoption costs range from $\$ 7,000$ to $\$ 30,000$ (US DHHS, 2004a). Adoptive parents are subject to extensive background investigations and may face long waiting periods that vary greatly depending on the child's, the birth parents', and the adoptive parents' circumstances. Moreover, adoptive parents face risks in terms of the child's fit within their family. In light of these factors, federal and state governments support adoptive parents by offering incentives in the form of tax credits and tax exclusions, as well as adoption subsidies and reimbursements. ${ }^{2}$

The impact of public policies on foster care, adoption, and child welfare outcomes have

\footnotetext{
${ }^{2}$ The federal adoption tax credit is offered to families adopting a child with special needs from foster care which was set at $\$ 12,150$ per child for the 2009 tax year. In addition, some employers provide adoption benefits to their employees, and several agencies make adoption loans and grants available to couples undertaking child adoption.
} 
been extensively studied. ${ }^{3}$ Such policies date back to 1935 Title IV-B of the Social Security Act (SSA) which "provided federal funding to states for a broad range of preventive and protective child welfare services for abused and neglected children" (Allen and Bissell, 2004). Next, Title IV-E of the SSA was introduced with the Adoption Assistance and Child Welfare Act of 1980 and it established the federal Foster Care and Adoption Assistance Program. Avery (1998) provides an overview of the Act, its subsequent amendments, and its implementations by the states. In the early 1980s, following the passage of this Act, there was indeed a decline in the number of children in foster care (Waldfogel, 2004).

This trend, however, did not last long. Swann and Sylvester (2006) report that foster care caseloads more than doubled from 1985 to 2000. They attribute 31 percent of this growth in caseloads to higher female incarcerations during that period. Falling welfare benefits account for another 15 percent of the growth. Similarly, Bitler et al. (2006) report that the welfare reforms of the 1990s were associated with more children living in foster care. In 1997, President Bill Clinton signed the Adoption and Safe Families Act (ASFA) into law. Besides other changes in policies, this Act regulated the termination of parental rights (TPR) in an effort to reduce the likelihood that children stay in foster care for extended periods of time. A child in foster care cannot be adopted until the date of TPR. The ASFA seems to have reduced the foster care caseloads by giving states incentives to move children out of foster care and into adoption and other permanent placements (Swann and Sylvester, 2006). Others have investigated different factors, such as the increased availability of contraception methods and the legalization of abortion, that have influenced the supply of adoptable children and eventually the adoption rates (e.g. Gennetian, 1999; Bitler and Zavodny, 2002; Bernal et al., 2008).

State child welfare agencies offer financial compensation to adoptive parents in the form of adoption subsidies which are often financed by contributions from the federal government. Such subsidies are claimed to be "the single-most powerful tool used by the child welfare system to encourage adoption" (Gibbs et al., 2006). Gibbs et al. (2006) and Hansen (2008a) discuss the wide variation across states in terms of the design of their subsidy programs. Similarly, Hansen (2007a) shows that the states change the amount of the subsidy in an effort to promote adoption in the case of special needs children. Special needs criteria are based on the child's characteristics that typically include age, race, ethnicity, sibling groups, disabilities, among

\footnotetext{
${ }^{3}$ Bernal et al. (2008) provide an excellent review of child adoption in the context of institutional background and historical trends in the US for the period of 1951-2002.
} 
others; however, each state sets its criteria within broad federal guidelines. Dalberth et al. (2005) show that the adoption subsidies vary widely with the child's as well as the adoptive parent's characteristics. Researchers have exploited the variation in adoption subsidies within states over time to evaluate their impact on adoption outcomes. Using data from the 1996-2003 Adoption and Foster Care Analysis and Reporting System (AFCARS), Hansen (2007b) shows that federal and state policies promoting adoption of children from foster care significantly increase the demand for adoption. She finds that an increase of $\$ 100$ in average adoption assistance payments would have reduced the number of children waiting in foster care by almost 4,200 per year.

State child welfare agencies also offer financial compensation to the foster caregiver families or institutions. These financial incentives take the form of basic monthly foster care payments. The average figures indicate that the subsidies compensate foster caregivers about 56 to 77 percent of their monthly expenditures for a 9 to 11 year old child, depending on the level of family income (Doyle and Peters, 2007). Hence, the subsidies constitute a significant portion of the monetary costs associated with childrearing and seem to improve the placement of foster children (Doyle and Peters, 2007; Duncan and Argys, 2007). It is important to note that not only is adoption cheaper than foster care (in terms of monthly subsidies), but it might also yield better outcomes than foster care placement. Barth et al. (2006) perform a careful comparison of long-term foster care with adoption using propensity score matching method. They find that the cost of foster care to the government is on average twice as much as the cost of adoption.

Doyle (2007) also reports significant adverse effects of foster care on child outcomes for school-age children and youth. Using an instrumental variable approach to identify causal effects of foster care on long-term outcomes, he finds that children in foster care have higher delinquency rates, higher teen birth rates, and lower earnings. Another cost-benefit analysis carried out by Hansen (2008b) indicates that adoptions provide far greater long-term benefits. Her analysis takes into account a wide range of outcomes including the child's health, behavior, education, criminal activity, and employment. The estimated total private benefits range between $\$ 88,000$ and $\$ 150,000$ while the estimated total public benefits are even larger, about $\$ 190,000$ to $\$ 235,000$ in 2000 dollars. Her findings indicate that, from the public policy point of view, a dollar spent on adoption from foster care yields about three dollars in benefits. 


\subsection{Literature on ART Utilization}

The second strand of literature related to our paper is on the use of ART, evaluating how the increased availability of treatments influenced ART utilization, fertility rates, and other outcomes. Most of these studies exploit the variation in state-level infertility insurance mandates. Bitler and Schmidt (2006) use pooled waves of the NSFG for the period of 1982-2002. They report significant racial, ethnic, and socio-economic disparities in access to infertility treatment. In particular, white and highly educated women are significantly more likely to seek medical treatment to become pregnant. However, they do not find any evidence that the mandates increased ART utilization. Schmidt (2007) uses the Vital Statistics Detail Natality Data (DND) files and the Census to study fertility rates between 1981 and 1999. She finds that the presence of a mandate increased birth rates among women over age 35 by about 8 percent. She claims that this is the case because older and more educated women not only having a higher demand for infertility treatment services, but also being more likely to have private health insurance.

Several other papers confirm that mandated insurance coverage has increased IVF availability and utilization. Bundorf et al. (2007) use the DND from 1981 to 1999, in conjunction with the clinic-level utilization data for the period of 1991-2001. They show that the use of infertility treatments is significantly greater in states adopting comprehensive versions of infertility insurance mandates. Henne and Bundorf (2008) use the 1990-2001 national clinic registry data and find that in states with comprehensive mandates, the increased access to reproductive therapies led to increased ART utilization rates as well as higher growth rates of utilization. Finally, Bitler and Schmidt (2009) focus on the effect of mandates on the utilization of treatments by older and more-educated women. Using pooled data from the 1982, 1988, 1995, and 2002 NSFG, they find that the mandates had a large and significant effect on utilization of infertility treatment for exactly this subsample of women without any visible effects for the entire female population of childbearing age.

Buckles (2007) examines the period of 1982-1999 using the DND along with the March Current Population Surveys (CPS). She confirms that the infertility insurance mandates increased the incidence of multiple births and the birth rate among older women (ages 35+) while the birth rates for younger women during the same period declined. In addition to encouraging women to delay childbirth, she claims that these mandates may have had far reaching consequences in the form of impacts on labor force participation, educational attainment, and 
marriage. The estimated effects of increased access to infertility treatments on being married and a woman's educational attainment are statistically significant but small. Machado and Sanz-de-Galdeano (2009) confirm these findings that the mandates led to delays in first births using data from the DND for the period of 1968-2004 and March CPS for the period of 19682008. In addition, they find that the women in states with insurance mandates have fewer children by the end of their reproductive lives compared to the women in control states.

Finally, Bitler (2008) analyzes the same data as Schmidt (2007), and focuses not only on fertility but also on infant health outcomes between 1981 and 1999. She shows that the insurance mandates led to significant increases in the number of twin deliveries. As mentioned previously, multiple gestations may lead to complications for both the babies and the mothers. She finds that the mandates increased the use of infertility treatment by older women which in turn lead to small, albeit statistically significant, negative impacts on health outcomes for both twins as well as singletons.

None of the studies mentioned above focuses on how adoptions and infertility treatment utilization might be related. Bernal et al. (2008) acknowledge that the availability of ART might be partly responsible for the decline in adoption rates, though not until about 1985 since the first successful IVF was implemented in 1981. They argue that the effect of ART utilization on the number of children adopted could be sizeable, but they do not formally estimate this relationship. To our knowledge, our study is the first to provide empirical evidence on the links between ART use and child adoption in the context of public policy.

\section{Data}

Our empirical analysis uses state-specific longitudinal data from 1999 to 2006 . The main variables of interest are the measures of ART utilization and child adoption. The former come from the national clinic registry data and were collected as a joint effort by the Centers for Disease Control and Prevention (CDC), the American Society for Reproductive Medicine (ASRM), and the Society for Assisted Reproductive Technology (SART). The adoption figures are obtained from the AFCARS. The analysis also includes several annual state-specific characteristics which were collected from various sources. The full list of sources and summary statistics are depicted in Table 1. 


\subsection{ART Utilization}

ART utilization figures were obtained from the CDC's annual ART Reports. ${ }^{4}$ These data refer specifically to ART procedures in which a physician surgically removes a woman's eggs, in order to combine them with sperm and then return them to her uterus. Among various ART techniques, IVF is the most common form. According to the 2006 report, IVF was the method of choice in 99.7 percent of all types of ART procedures using fresh non-donor eggs or embryos. Since 1995, each ART clinic that is a member of the SART is required to report certain indicators regarding its operations and success rates to the CDC as mandated by the Fertility Clinic Success Rate and Certification Act of 1992. Each year, the CDC publishes clinic-level data with a three-year lag to track the outcome of the cycles performed.

The ART cycles performed correspond to the year in which they started. The data include information on the number of cycles performed as well as pregnancy and birth rates by various age groups. Our key outcome measure is the number of ART cycles performed using fresh non-donor egg transfers. ${ }^{5}$ As described in Table 1, this measure displays great variation across states and years. We normalize this measure (as well as the adoption figures) by the number of childbearing age women $(25-44)$ in each state by year. ${ }^{6}$ Specifically, the main ART utilization measure in this paper is the number of ART cycles performed per 1,000 women, which steadily increased from 1.42 in 1999 to 1.92 in 2006 in our sample.

As part of our empirical analysis, we restrict our attention to women who are ages 35 or older $(35+)$ since impaired fecundity becomes more pronounced for this age group, well before the onset of menopause. Moreover, ART is less effective among older women: on average, it takes less than three ART cycles per one live birth when all women are considered, while about five ART cycles are performed per one live birth among older women $(35+)$. We construct an additional outcome measure for the number of ART cycles performed for women who are ages 35 or older and adjust this measure by the number of women in the same age group. This outcome measure rose somewhat faster from 1.40 in 1999 to 1.96 in 2006, with an overall average of 1.72. Finally, we proxy the "availability of ART procedures," using the number of

\footnotetext{
${ }^{4}$ CDC ART Reports are publicly available online at http://www.cdc.gov/ART.

${ }^{5}$ In 2006, the most commonly performed ART cycles were transfers using fresh non-donor eggs/embryos (72 percent), followed by frozen non-donor eggs/embryos (16 percent), and lastly fresh and frozen donor eggs/embryos (eight and four percent, respectively). In our robustness checks, we provide analyses based on these alternative measures of ART cycles performed.

${ }^{6}$ Normalizing variables by 1,000 births instead of 1,000 women leaves our results unchanged.
} 
ART clinics for a given state and year (per 1,000 women). ${ }^{7}$ On average, there are about 7.5 clinics (or 8.8 per 1,000,000 women), while there is great variation across states and years.

There are a few data limitations that need to be mentioned. First, the CDC ART reports lack information on individual ART users. As a result, an increase in the number of cycles performed could be due to an increase in the number of users and/or higher number of trials per user. However, focusing on the number of ART cycles rather than the number of ART users is more policy relevant since the cost of utilization depends on the former. Another shortcoming of the CDC ART reports is the lack of figures on the utilization of infertility treatments other than ART, such as ovulation stimulating drugs and surgical repair of reproductive organs. Schmidt (2007) reports that most instances of impaired fecundity are treated by these less invasive therapies with costs ranging from $\$ 200$ to $\$ 3,000$ per treatment. Given the considerably lower cost of such alternative treatments, individuals with impaired fecundity would presumably use these kinds of infertility services before considering adoption or ART. Hence, we do not expect to see any significant relationship between child adoption and the utilization of infertility treatments other than ART.

\subsection{Adoption and Foster Care}

Data on adoption measures come from the AFCARS which is a federal source of childspecific information on all children covered by the protections of Title IV-B and Title IV-E of the SSA (NDACAN, 2007). Since 1995, states have been submitting data to the US Children's Bureau on a semi-annual basis, concerning each child in foster care and each child who has been adopted under the authority of the state's child welfare agency. The AFCARS database has been designed to address policy development and program management issues at both the state and federal levels. It contains one file with the adoption data and another file with the foster care data for each year. ${ }^{8}$ The data correspond to the reporting period of federal fiscal years, i.e. starting on October $1^{\text {st }}$ and ending on September $30^{\text {th }}$ of the following year. ${ }^{9}$

The AFCARS has some limitations. First, in the years prior to FY1998, some states

\footnotetext{
${ }^{7}$ Since it is not the primary focus of our analysis, the number of ART clinics is treated as exogenously given. Hamilton and Brian McManus (2007) provide an analysis of the market structure for infertility treatment and examine the determinants of new ART clinic entry.

${ }^{8}$ Information on how to obtain permission to use the AFCARS database can be found at http://www.ndacan.cornell.edu/NDACAN.

${ }^{9}$ For example, the 2005 data corresponds to October 2004 through September 2005. The 2005 AFCARS adoption file is then merged with 2005 CDC ART report which corresponds to the 2005 calendar year. Note that this accords well, since we focus on the effect of adoption on ART utilization as explained in further detail below.
} 
did not report any adoption or foster care data and other states have incomplete data. For this reason, our analysis covers the period from 1999 to 2006 and the panel includes 378 state-year observations. ${ }^{10}$ Second, the adoption figures reflect only the children adopted under the authority of the state child welfare agency which accounts for about a third of all child adoptions in the US (US DHHS, 2004b). The process of child adoption takes a variety of forms as the children could be adopted through private or public agencies and from domestic or international sources. The AFCARS does not contain figures on international adoptions or domestic private agency adoptions. Our calculations using the 2007-2008 National Survey of Adoptive Parents (NSAP) reveal that the share of foster care adoptions is about 37 percent, while private agency adoptions constitute 38 percent of all adoptions, and the remaining 25 percent are international adoptions. In what follows, we provide descriptive statistics based on the NSAP and conjecture that our estimates using the AFCARS constitute a lower bound of the true effect of adoption rates on ART use. In addition, we provide evidence in support of this argument using data on international adoptions from the Department of State.

Despite its shortcomings, the AFCARS is still the only data source available on adoption figures along with adoption subsidies that are consistent across states and over time. The adoption file contains information on adopted children including their gender, race, birth date, ethnicity, and prior relationship with the adoptive parents. There is also limited information on the characteristics of the birth and adoptive parents. In this paper, we consider only the number of child adoptions by unrelated individuals and later provide a robustness exercise using the number of adoptions by relatives. Based on the number of adoptions of unrelated children, we form several outcome measures. In addition to considering all unrelated adoptions, we also decompose this number by the age of the adoptive mother as well as by the age of the adopted child. The motivation for the subsample of women ages 35 and older (35+) was explained above. We also study the adopted children who are above age five $(5+)$ as an additional subsample. Individuals may pursue ART as a means to having children because they might have a stronger preference for biologically linked children and also because they might be particularly interested in raising an infant. If so, adoptions of younger children would

\footnotetext{
${ }^{10}$ Mainly due to missing information on adoption subsidies, Nevada and New York are excluded from our sample together with 14 other state-year observations. The OLS and FE estimations can be carried out using data on 400 observations. However, the FE-2SLS estimations require information on the number and composition of the children in foster care waiting to be adopted. To allow for ease of comparison, we report the OLS and FE results for the sample with 378 observations. The results based on the full sample of 400 observations are virtually identical to those reported below.
} 
be considered a more appropriate substitute to ART. We normalize each of these adoption figures by the number of women (and the number of women 35+), and these child adoption rates are the primary explanatory variables of interest in our empirical analysis.

The average number of unrelated children adopted in our sample is 711 . The average figure for children adopted by older adoptive mothers $(35+)$ is 562 , constituting almost 80 percent of all adoptions. The normalized figures indicate that, on average, there is one child adopted per 1,000 women (aged 25-44). When we consider the adoptions by older women only, on average, there are 1.5 child adoptions per 1,000 women (aged 35-44). These figures suggest that adoptions are more popular among older individuals who are more likely to suffer from impaired fecundity and for whom ART is a relatively more costly and less successful alternative. During the period we consider, children adopted under the age of five constitute 43 percent of all adoptions.

An important piece of information contained in the AFCARS adoption file is the adoption subsidies provided to the adoptive parents under adoption assistance agreements. Under such agreements, adoptive parents may receive monthly payments, medical coverage, and other services depending on the state and county policies if they adopt a child who meets certain eligibility requirements. According to the US Department of Health and Human Services, 89 percent of all children adopted during FY2006 received adoption subsidies (US DHHS, 2008). Most of these subsidies are federally funded under Title IV-E of the SSA. In addition, state and/or county funded subsidies might be available even if an adoption does not qualify for the Title IV-E subsidies. Using the AFCARS figures, which reflect the subsidies effective at the time the adoption is finalized, we construct average monthly adoption subsidies (in real 2000 US\$100s). ${ }^{11}$ The average monthly adoption subsidy in our sample is about $\$ 470$. Note that the adoptive parents continue to receive these subsidies typically until the child reaches age 18 . Thus, they could be sensitive to even small variations in adoption subsidies.

The foster care file of the AFCARS contains information on children in foster care including their gender, birth date, race, ethnicity, and availability for adoption. As can be seen in Table 1, the average number of children in foster care is much higher than the average number of adoptions: only about six percent of children at foster care end up being adopted. This is partly due to the fact that it is not straightforward to match the children in foster

\footnotetext{
${ }^{11}$ Following Dalberth, Gibbs, and Berkman (2005), we set the monthly subsidy amount to missing in the few cases when they were reported as greater than $\$ 10,000$.
} 
care with adoptive families. Another important reason is that not all children in foster care are considered adoptable as many of them are kept to be reunited with their biological parents and are thus not available for adoption. We construct a measure of the "supply of adoptable children" using the number of children in foster care waiting to be adopted. This measure is also adjusted by the number of women in a given state and year. We use the gender and age composition of these children as additional identifying variables. As Hansen (2007b, p.382) points out, the matching of adoptable children and adoptive parents depends on "attributes of both the adult population and the population of waiting children." Therefore, the composition of adoptable children may be an important factor if adoptive parents seek specific attributes when considering to adopt a child.

\subsection{State-Level Characteristics}

In all of our analyses, we include a number of state-level characteristics to account for the demographic and economic conditions that could be related to child adoptions as well as ART utilization. The 2000 Census figures indicate that adoptive children, compared to biological children, are more likely to live with white, married couples with higher educational attainment, home ownership rates, and household income (Kreider, 2003). Similarly, women who utilize infertility treatment have on average higher income and educational attainment, are more likely to be white and to have health insurance coverage compared to the rest of the infertile women (Stephen and Chandra, 2000; Bitler and Schmidt, 2006; Farley Ordovensky Staniec and Webb, 2007; Hammoud et al., 2009). Given that the state fixed effects remove any unobservable timeinvariant state-specific factors, the effects of all these state-specific characteristics are solely identified via within-state variation over time.

The state-level variables in our analysis include the number of ART clinics per 1,000 women; the share of the total resident population covered by private health insurance; real income per capita; the percentage share of the total resident population with at least a college degree; the teen birth rate; the race ratio of the resident population (defined as blacks over whites); and the ratio of female resident population between the ages of 35-44 to those between the ages of 25-44. This last variable indicates the portion of the females with deteriorated fecundity among women of childbearing age. Female labor force participation rates play a crucial role in determining the demand for children and thus are included as an additional explanatory variable. 
We also include a dummy variable that equals one if the state has adopted health insurance mandates for infertility treatments. Such mandates provide an exogenous source of variation in the out-of-pocket cost of ART procedures, but most of the states have passed the mandates in earlier years. During this period, only Louisiana and New Jersey passed mandates, both in 2001. Due to this reason, it is not possible to carry out an alternative analysis of how infertility insurance mandates influence adoption rates. Note that this type of an empirical work would identify a different policy parameter, i.e. how policies regarding health insurance coverage or regulations in the ART markets affect child adoption rates. We, on the other hand, are interested in identifying how public policies through child welfare programs influence ART users who marginally prefer ART to child adoption.

\section{Empirical Framework and Results}

\subsection{Empirical Framework}

To conceptualize our estimation equations, we first present a simple framework. Suppose that women of childbearing age in a given state and year are distributed according to a joint distribution of four variables, $U_{0}, U_{b}, U_{t}$, and $U_{a}$. Let $U_{0}$ denote the indirect utility of a woman when she remains without a(n additional) child and let $U_{b}, U_{t}$, and $U_{a}$ denote the expected utility when she attempts to have an additional child through natural birth, ART, and adoption, respectively. Next, we define the following probabilities:

$$
\begin{aligned}
& \pi_{0}=\operatorname{Pr}\left(U_{0}>U_{b}, U_{0}>U_{t}, U_{0}>U_{a}\right) \\
& \pi_{b}=\operatorname{Pr}\left(U_{b}>U_{0}, U_{b}>U_{t}, U_{b}>U_{a}\right) \\
& \pi_{t}=\operatorname{Pr}\left(U_{t}>U_{0}, U_{t}>U_{b}, U_{t}>U_{a}\right) \\
& \pi_{a}=\operatorname{Pr}\left(U_{a}>U_{0}, U_{a}>U_{b}, U_{a}>U_{t}\right)
\end{aligned}
$$

Each probability, $\pi_{j}$, represents the proportion of women who choose option $j .{ }^{12}$ Consequently, $\pi_{t} N$ is the number of women who choose to use ART to have a child, where $N$ is the total number of childbearing age women in a given state and year. One empirical implication of this set-up is that a simple cross-sectional relationship between ART utilization $\left(\pi_{t}\right)$ and adoption $\left(\pi_{a}\right)$ might be spurious if the other two probabilities, $\pi_{0}$ and $\pi_{b}$, are omitted from the

\footnotetext{
${ }^{12}$ The probabilities are represented by integration over the distribution. For example, we have $\pi_{0}=$ $\iint_{U_{a}<U_{0}} \int_{U_{t}<U_{0}} \int_{U_{b}<U_{0}} f\left(U_{0}, U_{b}, U_{t}, U_{a}\right) d U_{b} d U_{t} d U_{a} d U_{0}$, where $f$ denotes the joint distribution.
} 
analysis. For example, if there is an increasing trend of childless marriages, this alone will lead to a positive correlation between $\pi_{t}$ and $\pi_{a}$.

Now suppose that there is an increase in the adoption subsidy (or any exogenous shock) that makes adoption more attractive compared to other options, holding everything else constant. Let $s>0$ denote the corresponding increase in $U_{a}$. It is difficult to think of any plausible scenario in which such a change would have an impact on ART utilization rates except through their effect on child adoptions. Therefore, there is no reason for $U_{j}, j \neq a$, to change. The probabilities after the new adoption subsidy can be expressed as follows:

$$
\begin{aligned}
\pi_{0}^{\prime} & =\pi_{0}-\operatorname{Pr}\left(U_{0}>U_{b}, U_{0}>U_{t}, U_{a}<U_{0}<U_{a}+s\right) \\
\pi_{b}^{\prime} & =\pi_{b}-\operatorname{Pr}\left(U_{b}>U_{0}, U_{b}>U_{t}, U_{a}<U_{b}<U_{a}+s\right) \\
\pi_{t}^{\prime} & =\pi_{t}-\operatorname{Pr}\left(U_{t}>U_{0}, U_{t}>U_{b}, U_{a}<U_{t}<U_{a}+s\right) \\
\pi_{a}^{\prime} & =\pi_{a}+\left(\pi_{0}-\pi_{0}^{\prime}\right)+\left(\pi_{b}-\pi_{b}^{\prime}\right)+\left(\pi_{t}-\pi_{t}^{\prime}\right)
\end{aligned}
$$

There are some women who start to seek adoption, $\left(\left(\pi_{0}-\pi_{0}^{\prime}\right)+\left(\pi_{b}-\pi_{b}^{\prime}\right)+\left(\pi_{t}-\pi_{t}^{\prime}\right)\right) N$, where $\left(\pi_{t}-\pi_{t}^{\prime}\right) N$ represents those who switch from ART to adoption. Thus, the following term allows us to gauge the degree of substitutability between ART use and adoption:

$$
\frac{\left(\pi_{t}-\pi_{t}^{\prime}\right) / \pi_{t}}{\left\{\left(\pi_{0}-\pi_{0}^{\prime}\right)+\left(\pi_{b}-\pi_{b}^{\prime}\right)+\left(\pi_{t}-\pi_{t}^{\prime}\right)\right\} / \pi_{a}}
$$

The numerator above indicates the percentage change in the number of women who use ART, while the denominator represents the percentage change in the number of women who decide to adopt as a result of the policy. ${ }^{13}$ This term, which can be interpreted as an elasticity, is what we aim to identify.

The existence of a measurable mass of $\left(\pi_{t}-\pi_{t}^{\prime}\right) N$ requires that there are at least some women who do not have lexicographic preferences, and therefore, may be willing to switch between ART and adoption in response to policy changes. Our calculations using the 2002 NSFG suggest that there might be significant overlaps in the population of women who seek medical assistance with getting pregnant and those women who adopt an unrelated child. The former are more likely to be infertile (29 compared to 23 percent), white ( 83 versus 78 percent), and college educated (79 compared to 66 percent). However, there are no statistically significant

\footnotetext{
${ }^{13}$ We assume that in both ART and adoption markets the equilibrium quantity is determined by the demand.
} 
differences in terms of age (36 compared to 38), labor force participation (76 compared to 74 percent), or full-time work status (47 percent for both).

Whether there are some women who switch from ART to adoption is an empirical question. To test this, we specify the following equation determining ART utilization:

$$
A R T_{s, t}=\beta A d o p t_{s, t}+X_{s, t} \gamma+\mu_{1, t}+\nu_{1, s}+v_{s, t},
$$

where the dependent variable is the number of ART cycles undertaken in state $s$ and year $t$, normalized by 1,000 women aged 25-44. Adopt $t_{s, t}$ is the number of unrelated adoptions in state $s$ in year $t$, which is also normalized. Our main interest is the estimate of $\beta$ which quantifies the average elasticity of ART cycles performed with respect to adoptions. The vector $X$ includes various state characteristics as listed above that may impact ART use. Equation (2) also includes year fixed effects $\left(\mu_{1, t}\right)$ and state fixed effects $\left(\nu_{1, s}\right)$. The former capture any nationwide trend in infertility treatment utilization, while the latter pick up any unobserved time-invariant state heterogeneity. Lastly, $v_{s, t}$ is a standard error term.

An econometric problem here, as our conceptual framework indicated, is the potential endogeneity of Adopt because child adoption and ART utilization are related choices. For example, if there is an unobservable trend towards smaller families, then the unobservables will be negatively correlated with both ART use and child adoptions. Under this or a number of other plausible scenarios, we conjecture that a regression of ART use on adoption rates might bias the estimated elasticity upwardly towards zero, underestimating how much individuals might substitute ART use for adoptions. As Doyle and Peters (2007) point out, this problem may be resolved to a degree with the inclusion of state and year fixed effects. However, to better address the potential endogeneity issue, we also use a fixed effects two-stage least squares method (FE-2SLS). Specifically, we estimate the following first-stage equation:

$$
\begin{array}{r}
\text { Adopt }_{s, t}=\alpha_{1} \text { Subsidy }_{s, t}+\alpha_{2} \text { KidsWait }_{s, t}+\alpha_{3} \text { PercGirls }_{s, t} \\
+\alpha_{4} \text { PercInfants }_{s, t}+X_{s, t} \delta+\mu_{2, t}+\nu_{2, s}+\varepsilon_{s, t}
\end{array}
$$

where the adoption rate is formally modeled as a function of adoption policy and foster care variables in addition to state fixed effects $\left(\nu_{2, s}\right)$, year fixed effects $\left(\mu_{2, t}\right)$, and state characteristics that are included in the second-stage equation.

The instrumental variables are selected based on previous findings. The literature on 
child adoption reviewed above has documented that the adoption rate significantly depends on the number of adoptable children (Gennetian, 1999; Bitler and Zavodny, 2002; Bernal et al., 2008) and the policy variables that influence the cost of adoption, including the adoption subsidies (Doyle and Peters, 2007; Duncan and Argys, 2007; Hansen, 2007b). We include four instrumental variables (IVs): Subsidy, KidsWait, PercGirls, and PercInfants. There is substantial variation in average monthly adoption subsidies within states over time since states can define their criteria for special needs. In addition, Hansen and Pollack (2005) show that the subsidy payments typically result from a bargaining process between the child welfare authority and the adoptive family. Thus, subsidies vary due to variation in the characteristics of children waiting to be adopted, too. For robustness, we also use an alternative measure: the basic adoption assistance rates for 2-year-olds as previously utilized by Hansen (2007b). These basic rates are utilized as benchmark amounts in the bargaining processes and the data are collected by the North American Council on Adoptable Children (NACAC). The AFCARS, on the other hand, contains the actual rates effective at the time of adoption finalization and thus display greater variation. ${ }^{14}$

While KidsWait indicates the number of children in foster care waiting to be adopted, PercGirls and PercInfants reflect the demographic composition of these children, all measured at the end of previous fiscal year. The last two variables are defined as the percentage of girls and percentage of children under age five who are in foster care waiting to be adopted, respectively. The number of children waiting to be adopted (KidsWait) represents the supply. Given that there is an excess supply of children waiting for adoption, one may expect that an increase in KidsWait would not necessarily affect the number of children finally adopted. However, a higher number of adoptable children improves the matching quality between children and adoptive parents and, as a result, increases the number of adoptions. Moreover, the number of children waiting to be adopted might directly or indirectly affect the monetary or non-monetary costs of adoption as well as the decision processes regarding casegoal determination for the foster care children. In addition to the definition of special needs and the determination of monthly subsidy rates, Bower and Laws (2002) identify a dozen of other policy tools that are used by the states to support adoptive parents. These include, but are not lim-

\footnotetext{
${ }^{14}$ In our sample, a substantial portion of the variation in adoption subsidies is due to within state variations over time. The average monthly adoption subsidy is 4.73 with an overall standard deviation of 1.43 . The between states standard deviation is 1.27 and the within states standard deviation is 0.66 . The average basic adoption assistance rate (also measured in constant $2000 \$ 100 \mathrm{~s}$ ) is 3.81 with an overall standard deviation of 1.19 . The between states standard deviation is 1.11 and the within states standard deviation is 0.44 .
} 
ited to, various practices such as non-recurring adoption expense reimbursements, subsidized guardianships, subsidies for children over 18 years old, eligibility for Medicaid. Such variables are omitted from our analysis due to absence of state-specific data, but they are partially and indirectly captured by KidsWait.

The inclusion of the two demographic composition measures, PercGirls and PercInfants, is also motivated by the literature on "revealed preferences" for adopted children. First, it has been documented that girls are more likely to be adopted than boys (Kreider, 2003). The main reason for this is because adoptive mothers prefer girls over boys and because girls seem less risky to adopt (Groze, 1991; Chandra et al., 1999; Gravois, 2004). Accordingly, we would expect PercGirls to increase the adoption rate. Likewise, to the extent that adoptive parents prefer infants over older children, PercInfants is expected to be positively related to adoption rates. $^{15}$

The assumption is that our instruments do not directly affect ART use after controlling for various state characteristics as well as year and state fixed effects. It might be plausible that states determine monetary incentives, such as adoption subsidies, according to the number of children waiting in foster care or the number of children adopted. However, many researchers have defended the assumption of exogeneity, especially in the presence of state and year fixed effects (e.g. Hansen and Hansen, 2006; Doyle and Peters, 2007; Hansen, 2007b). Doyle and Peters (2007, p.343) argue that the subsidy rates are not set to clear the foster care market and state that they may rather be "set to partially reimburse foster parents for child expenditures and are often tied to rates set in other welfare programs."

Regarding the validity of KidsWait, one might consider the possibility that higher ART utilization rates could reduce adoption rates which, in turn, increase the number of children available for adoption. However, the suggested mechanism indicates a positive correlation between unobservables and ART utilization rates as well as with KidsWait, which implies that our FE estimate will be a lower bound of the true substitution effect in absolute terms. Furthermore, note that KidsWait, PercGirls, and PercInfants are all based on the foster care files which reflect the stock values at the end of each fiscal year, i.e., the number of children remaining in foster care as of September 30th, whereas adoption figures are flow variables reflecting the number of children who were adopted throughout the entire fiscal year. Therefore,

\footnotetext{
${ }^{15}$ We also tried including a measure of the racial composition for the foster children waiting to be adopted as an additional IV but this variable was never statistically significant.
} 
adoption variables are merged with foster care variables for the previous fiscal year. For example, 2005 adoption variables (corresponding to the period of October 2004 to September 2005) are merged with 2004 foster care variables (corresponding to the period of October 2003 to September 2004). The timing of these measures further support the validity of our IVs. Below, we present the results of formal diagnostic tests for the relevance and the exogeneity of the excluded instruments.

All equations are estimated using the total number of women as weights to reflect underlying microdata. In addition, standard errors are clustered by state in order to account for possible serial correlation in the error terms. We interpret our FE-2SLS estimates in the spirit of the local average treatment effect. The FE-2SLS estimate identifies the average response of individuals whose decision is influenced by the specific instrumental variables used in the analysis (Angrist and Imbens, 1995). In our case, the FE-2SLS estimate can be interpreted as the effect of one additional adopted child on the ART utilization for individuals whose decision to have children is influenced by the excluded IVs we utilize. These variables include public policy measures such as adoption subsidies. Therefore, even if these individuals might not be representative of the entire population, they represent the group whose infertility treatment utilization is responsive to public policies in terms of child adoption.

\subsection{Estimation Results}

In Table 2, we present the FE estimation results corresponding to equation (2) as well as the OLS results. Panel A displays the results for all unrelated adoptions, panel B for unrelated adoptions by older women (ages $35+$ ), and panel $\mathrm{C}$ for unrelated adoptions of older children (ages $5+$ ). Each column corresponds to a different specification: in column 1, the estimation method is OLS with control variables and year fixed effects, but no state fixed effects. Column 2 features the same specification as column 1 except that it includes state fixed effects. For brevity, the estimated coefficients on state and year fixed effects, as well as on the control variables are not reported. ${ }^{16}$ We focus on the estimated coefficient of our main interest, $\widehat{\beta}$. We report the coefficient estimate for the adoption variable followed by its standard error in parentheses and the implied elasticity in italics.

First, let us focus on the results for all unrelated adoptions and ART utilization in panel A of Table 2. The OLS model without state fixed effects (column 1) yields a positive coefficient

\footnotetext{
${ }^{16}$ The full set of results can be obtained from the authors upon request.
} 
on child adoptions that is only marginally statistically significant $(p<0.10)$. Including state fixed effects (column 2) yields a negative coefficient of about -0.22 which is highly significant $(p<0.01)$. The implied elasticity of ART use with respect to unrelated adoptions is about -0.13. A comparison between columns 1 and 2 reveals a pattern that is consistent with our conjecture that a cross-sectional correlation between adoption and ART utilization is likely to be spurious due to omitted variables related to $\pi_{0}$ or $\pi_{b}$. The FE estimate suggests that there is substitutability between these two options for having children.

Panel B in Table 2 presents the results for unrelated adoptions by older adoptive mothers (ages 35+). The implied elasticity of ART use with respect to adoptions (-0.17) is somewhat larger in absolute terms compared to the results presented in panel A. A higher responsiveness among older women is expected because ART success rates are lower for them. Since older women need to utilize more cycles for a successful delivery, an increase in adoptions will reduce the ART use more compared to younger women. Alternatively, older women might display weaker preference for biological children. The estimate in panel B is also statistically significant $(p<0.01)$. The final panel in Table 2 reports the results for the adoptions of older children (ages $5+)$. The FE estimate is about $-0.30(p<0.01)$ and yields an implied elasticity of -0.10 . This suggests a greater substitutability between ART use and infant adoption, likely reflecting strong preferences for infants among those who undertake ART.

Next, we present the findings from the FE-2SLS models. Table 3 displays the results for the first-stage equation (3). The odd numbered columns refer to the results using the IV set I (includes average monthly adoption subsidies from the AFCARS) while the even numbered columns report the results using the IV set II (includes basic adoption assistance rates for 2-year-olds from the NACAC). The first two columns present the results of our baseline specification based on all unrelated child adoptions. The results are consistent with our expectations: increases in the average amount of subsidies and the number of waiting children both significantly increase adoption rates. Our point estimates suggest that a $\$ 100$ increase in adoption subsidies would increase the unrelated adoption rate by 0.03 to 0.07 , depending on the specification. The implied elasticity is about 0.14 to 0.29 . These estimates are similar to those of Hansen (2007b) who estimated an elasticity of 0.16 . We also find that the adoption rates rise as PercGirls increases, indicating a preference for girls over boys. Finally, the adoption rates among older women $(35+)$ as well as the adoption rates of older children $(5+)$ both 
increase as PercInfants decreases. ${ }^{17}$ The instruments are all statistically significant, and the F-statistic for the joint significance ranges between 17 and 21. Based on Hansen's J statistics, we cannot reject the null hypothesis of over-identification.

Table 4 displays the results for our second-stage regressions. In panel $\mathrm{A}$, we start with all unrelated adoptions. Recall that the FE estimate reported in Table 2 is about -0.22 . The FE-2SLS estimates of $\beta$ in columns 1 and 2 of Table 4 indicate even larger effect sizes about -0.26 and -0.25 , respectively, and both are highly statistically significant $(p<0.01)$. This pattern again implies that there are unobserved factors that are correlated with both $A R T$ and Adopt in the same direction, such that the FE estimate is biased toward zero. The implied elasticity of ART utilization with respect to unrelated adoptions is - 0.15 -slightly larger in absolute terms. In panel $\mathrm{B}$, we restrict our attention to older adoptive mothers $(35+)$. The estimated coefficients are associated with somewhat larger elasticity figures in absolute terms, between -0.18 and -0.19. Finally, panel $\mathrm{C}$ displays the results for older adopted children (5+); the estimated elasticities are about -0.11 . Thus, once again, the adoption of older children seems to be a relatively weaker substitute for ART use.

There are some other findings worth noting, namely those regarding control variables included in the analysis (not reported). First, we find that one additional infertility specialty clinic per 1,000 women increases the number of cycles performed by about 66 per 1,000 women $(p<0.01)$. Second, the infertility insurance mandates increase ART utilization rates, but the effect is statistically insignificant possibly due to limited within-state variation. Third, the use of ART increases in per capita income $(p<0.05)$, which likely reflects the fact that a major obstacle to ART is the financial cost. Fourth, higher teen birth rates seem to significantly reduce ART utilization $(p<0.01)$, which might be picking up the effect of economic conditions and/or private agency adoptions on ART use. Lastly, ART utilization is also positively associated with the proportion of female resident population between the ages of 35-44 to those between the ages of 25-44 $(p<0.01)$. As explained before, this fraction represents the relative size of the female population experiencing relatively more severe fertility problems among all women of childbearing age.

\footnotetext{
${ }^{17}$ Note that to interpret the reported elasticities on these two variables one should consider a one unit change which implies a doubling of the variable given that they are expressed as fractions rather than percentages.
} 


\subsection{Robustness Checks}

Table 5 presents the results of separate robustness checks using FE models. First, we run a regression including both related and unrelated child adoptions. Related adoptions are quite different in nature than unrelated adoptions since the former are probably undertaken mostly due to motives independent of fertility status and economic factors (e.g., people adopting young offspring of their siblings or spouses). This exercise yields basically zero coefficient and elasticity estimates for related adoptions, while the coefficient on unrelated adoptions is virtually the same as reported above (panel A).

As discussed above, the AFCARS figures reflect foster care adoptions only, not all child adoptions. Our calculations using the NSAP reveals that foster care adoptions make up little more than a third of all adoptions. Those who adopt from foster care might be different than those who pursue international or private agency adoptions. In fact, the summary statistics using NSAP suggest that foster care adopters are less affluent compared to the rest, based on the level of their household income. Second, foster care adopters are less likely to suffer from infertility. About 38 percent of the foster care adopters report infertility, while the corresponding share is 52 and 72 percent for private agency and international adopters, respectively. Therefore, foster care adopters might be less likely to pursue ART suggesting again that our estimates would constitute lower bounds of the true effect of child adoption on ART use.

To test this conjecture, we obtained data on international adoptions from the Office of Children's Issues under the US Department of State. These data include the number of all children who received immigrant visas issued during a given fiscal year for the purpose of adoption in the US. On average, there were 0.5 international adoptions per 1,000 women during our period of analysis (see Table 1). Panel B in Table 5 reports the estimation results when we include international adoptions in addition to unrelated foster care adoptions as explanatory variables. The FE regressions of ART use yields a coefficient of - 0.761 on international adoptions $(p<0.05)$. The coefficient on unrelated foster care adoptions remains the same as before $(p<0.01)$. The estimated elasticity on international adoptions is -0.22 , indicating that changes in international adoptions have larger effects on ART use compared to domestic adoptions from foster care.

As a final exercise, we consider all ART cycles using non-donor and donor egg/embryo transfers including both fresh and frozen types. Inclusion of frozen non-donor embryo transfers 
together with the fresh non-donor ones does not affect the results (panel $\mathrm{C}$ ). The coefficient estimate is still highly statistically significant and the implied elasticity is about -0.13 . On the other hand, the regression using donor egg/embryo transfers (both fresh and frozen) reveals a negative but statistically insignificant coefficient estimate (panel D). This finding can be interpreted as evidence for no substitutability between adoptions and ART cycles performed using donor eggs/embryos only. This is first because such cycles are a small portion (12 percent) of all ART cycles performed. Second, they are presumably more costly due to even higher price tags as well as the additional difficulties associated with finding a donor.

\section{Conclusions}

The empirical evidence we present suggests that promoting adoption encourages some individuals to adopt rather than pursuing ART as a means to having children. While ART provides the individuals with the possibility of having children who are biologically linked to themselves, concerns have been voiced about how demanding these types of treatments are, not only financially but also physically and psychologically, considering the low odds of success. Given the high costs of keeping children in foster care, both in terms of the social services costs and the adverse long-term outcomes for the children involved, it might be socially desirable to implement policies in an effort to encourage child adoption. In addition, the regulations on child adoption and ART utilization need to be reviewed to level the playing field since adoptions are subject to relatively tougher restrictions. The issue of ART use lends itself to several controversial questions concerning who should have access to such technologies, who should pay for the treatments, and whether the providers should be regulated. These considerations need to be addressed given that ART not only impact women's birth and health outcomes, but also potentially their marriage, education, and career decisions.

Recently, Congress passed the Fostering Connections to Success and Increasing Adoptions Act of 2008. This legislation, among other things, allows for revisions in the adoption incentive programs including the Title IV-E adoption assistance. Our findings suggest that such changes in adoption and foster care policies may have significant long-term effects on child adoption rates and also on the utilization of ART. Similarly, changes in the infertility treatment markets may have significant consequences in terms of child adoption. Since the early 1980s, the availability of treatment options for infertility has been greatly expanded mainly due to rapid 
technological change and also due to some states enacting legislation regarding infertility treatment insurance. Currently, the House of Representatives is evaluating the Family Building Act, which proposes to expand the coverage for infertility treatment to those who work for firms that self-insure. In Europe, ART is being considered as a possible tool to increase fertility rates in an effort to mitigate the consequences of population ageing (Grant et al., 2006). In the future, new technological advances and increased competition among infertility clinics are expected to continue reducing the cost of ART and increasing utilization. The insights offered here suggest that such changes in ART markets may have unintended consequences on child adoption outcomes. 


\section{References}

[1] Allen, M. and M. Bissell. 2004. "Safety and Stability for Foster Children: The Policy Context," The Future of Children, 14, pp.49-73.

[2] Angrist, J. D. and W. N. Evans. 1999. "Schooling and Labor Market Consequences of the 1970 State Abortion Reforms," Research in Labor Economics, Vol 18, S. Polachek (ed.), Greenwich: JAI Press.

[3] Angrist, J. D. and G. Imbens. 1995. "Two-Stage Least Squares Estimation of Average Causal Effects in Models with Variable Treatment Intensity," Journal of the American Statistical Association, 90(430), pp.431-442.

[4] Archibold, R. C. 2009. "Octuplets, 6 Siblings, and Many Questions," New York Times, February 4.

[5] Avery, R. J. 1998. "Adoption Assistance under P.L. 96-272: A Policy Analysis," Children and Youth Services Review, 20(1/2), pp.29-55.

[6] Barth, R. P., C. K. Lee, J. Wildfire, S. Guo. 2006. "A comparison of the governmental costs of long-term foster care and adoption," Social Service Review, 80(1), pp.127-158.

[7] Bernal, R., L. Hu, C. Moriguchi, and E. Nagypal. 2008. "Child Adoption in the United States: Historical Trends and the Determinants of Adoption Demand and Supply, 19512002" Working Paper.

[8] Bitler, M. P. 2008. "Effects of Increased Access to Infertility Treatment on Infant and Child Health: Evidence from Health Insurance Mandates," Working Paper.

[9] Bitler, M. P., J. Gelbach, H. Hoynes. 2006. "Welfare Reform and Children's Living Arrangements," Journal of Human Resources, 41(1), pp.1-27.

[10] Bitler, M. P. and L. Schmidt. 2006. "Health Disparities and Infertility: Impacts of StateLevel Insurance Mandates," Fertility and Sterility, 85(4), pp.858-865.

[11] Bitler, M. P. and L. Schmidt. 2009. "Utilization of Infertility Treatments: The Effects of Insurance Mandates," Working Paper.

[12] Bitler, M. P. and M. Zavodny. 2002. "Did Abortion Legalization Reduce the Number of Unwanted Children? Evidence from Adoptions," Perspectives on Sexual and Reproductive Health, 34(1), pp.25-33.

[13] Bower, J. W. and R. Laws. 2002. Forever Families: Support for families of children with special needs-A policy analysis of adoption subsidy programs in the United States, St. Paul, MN: North American Council on Adoptable Children. 
[14] Buckles, K. 2007. "Stopping the Biological Clock: Infertility Treatments and the CareerFamily Tradeoff," Working Paper.

[15] Buckles, K. 2008. "Understanding the Returns to Delayed Childbearing for Working Women," American Economic Review Papers and Proceedings, 98(2), pp.403-407.

[16] Bundorf, M. K., M. Henne, and L. Baker. 2007. "Mandated Health Insurance Benefits and the Utilization and Outcomes of Infertility Treatments," NBER Working Paper No. 12820.

[17] Caplan, A. 2009. "Ethics and octuplets: Society is responsible," Philadelphia Inquirer, February 6.

[18] Caucutt, E. M., N. Guner, and J. Knowles. 2002. "Why Do Women Wait? Matching, Wage Inequality, and the Incentives for Fertility Delay," Review of Economic Dynamics, 5, pp.815-855.

[19] Centers for Disease Control and Prevention (CDC). Various years. Assisted Reproductive Technology Success Rates: National Summary and Fertility Clinic Reports, Atlanta, GA: CDC.

[20] Chandra, A., J. C. Abma, P. Maza, and C. A. Bachrach. 1999. "Adoption, Adoption Seeking, and Relinquishment for Adoption in the United States," Vital Health Statistics, No. 306.

[21] Chandra, A., G. M. Martinez, W. D. Mosher, J. C. Abma, and J. Jones. 2005. "Fertility, family planning, and reproductive health of US women: Data from the 2002 National Survey of Family Growth," Vital Health Statistics, 23(25), pp.1-160.

[22] Cohen, M. 2009. "A Search for a Surrogate Leads to India," Wall Street Journal, October 8.

[23] Collins, J. 2001. "Cost-effectiveness of in vitro fertilization," Seminars in Reproductive Medicine, 19(3), pp.279-89.

[24] Dalberth, B., D. Gibbs, and N. Berkman. 2005. Understanding adoption subsidies: An analysis of AFCARS data. Washington, DC: Office of the Assistant Secretary for Planning and Evaluation (ASPE), US Department of Health and Human Services.

[25] Doyle, J. J. Jr. 2007. "Child Protection and Child Outcomes: Measuring the Effects of Foster Care," American Economic Review, 97(5), pp.1583-1610.

[26] Doyle, J. J. Jr. and H. E. Peters. 2007. "The market for foster care: an empirical study of the impact of foster care subsidies," Review of Economics of the Household, 5(4), pp.329351. 
[27] Duncan, B. and L. Argys. 2007. "Economic Incentives and Foster Care Placement," Southern Economic Journal, 74(1), pp.114-142.

[28] Farley Ordovensky Staniec, J. and N. J. Webb. 2007. "Utilization of Infertility Services: How Much Does Money Matter?" Health Services Research, 42(3), pp.971-989.

[29] Gennetian, L. A. 1999. "The Supply of Infants Relinquished for Adoption: Did Access to Abortion Make a Difference?" Economic Inquiry, 37(3), pp.412-431.

[30] Gibbs, D. A., B. T. Dalberth, N. D. Berkman, and D. Weitzenkamp. 2006. "Determinants of Adoption Subsidies," Adoption Quarterly, 9(2/3), pp.63-80.

[31] Goldin, C. and L. F. Katz. 2002. “The Power Of The Pill: Contraceptives and Women's Career and Marriage Decisions," Journal of Political Economy, 110(4), pp.730-770.

[32] Grant, J., S. Hoorens, F. Gallo, and J. Cave. 2006. Should ART Be Part of a Population Policy Mix? A Preliminary Assessment of the Demographic and Economic Impact of Assisted Reproductive Technologies. RAND Documented Briefing DB-507-FER. Cambridge, UK: RAND Europe.

[33] Gravois, J. 2004. "Bringing Up Babes. Why do adoptive parents prefer girls?," Slate, January 16.

[34] Groze, V. 1991. "Adoption and single parents: a review," Child Welfare, 70(3), pp.321-332.

[35] Hamilton, B. H. and B. McManus. 2007. "Infertility Treatment Markets: The Effects of Competition and Policy" Working Paper.

[36] Hammoud, A. O., M. Gibson, J. Stanford, G. White, D. T. Carrell, and M. Peterson. 2009. "In vitro fertilization availability and utilization in the United States: a study of demographic, social, and economic factors," Fertility and Sterility, 91(5), pp.1630-1635.

[37] Hansen, M. E. 2007a. "State-Designated Special Needs, Post-Adoption Support, and State Fiscal Stress," Children and Youth Services Review, 29, pp.1411-1425.

[38] Hansen, M. E. 2007b. "Using Subsidies to Promote the Adoption of Children from Foster Care," Journal of Family and Economic Issues, 28(3), pp.377-393.

[39] Hansen, M. E. 2008a. "The distribution of a federal entitlement: the case of adoption assistance," Journal of Socio-Economics, 37, pp.2427-2442.

[40] Hansen, M. E. 2008b. "The Value of Adoption," Adoption Quarterly, 10(2), pp.65-87.

[41] Hansen, M. E. and B. A. Hansen. 2006. "The economics of adoption of children from foster care," Child Welfare, 85(3), pp.559-583. 
[42] Hansen, M. E. and D. Pollack. 2005. "Unintended consequences of bargaining for adoption assistance payments," Family Court Review, 43(3), pp.495-511.

[43] Henne, M. B. and M. K. Bundorf. 2008. "Insurance mandates and trends in infertility treatments," Fertility and Sterility, 89(1), pp.66-73.

[44] Kane, T. J. and D. Staiger. 1996. "Teen Motherhood and Abortion Access," Quarterly Journal of Economics, 111(2), pp.467-506.

[45] Kreider, R. M. 2003. Adopted Children and Stepchildren: 2000. Census Special Reports, CENSR-6RV. Washington, DC: US Census Bureau.

[46] Machado, M. P. and A. Sanz-de-Galdeano. 2009. "Coverage of Infertility Treatment and Fertility Outcomes: Do Women Catch Up?," Working Paper.

[47] National Center for Health Statistics (NCHS). 1999. "Trends in twin and triplet births: 1980-97," Vital Health Statistics, 47, pp.1099-1120.

[48] National Data Archive on Child Abuse and Neglect (NDACAN). 2007. AFCARS, 2000present, User's Guide and Codebook. Ithaca, NY: NDACAN.

[49] Neumann, P. J. 1997. "Should Health Insurance Cover IVF? Issues and Options," Journal of Health Politics, Policy and Law, 22(5), pp.1215-1239.

[50] Neumann, P. J., S. D. Gharib, and M. C. Weinstein. 1994. "The Cost of a Successful Delivery with in Vitro Fertilization," New England Journal of Medicine, 331(4), pp.239243.

[51] Schmidt, L. 2007. "Infertility Insurance Mandates and Fertility," American Economics Review Papers and Proceedings, 95(2), pp.204-208.

[52] Stephen, E. H. and A. Chandra. 2000. "Use of Infertility Services in the United States: 1995," Family Planning Perspectives, 32, pp.132-137.

[53] Swann, C. A. and M. S. Sylvester. 2006. "The Foster Care Crisis: What Caused Caseloads to Grow?" Demography, 43(2), pp.309-335.

[54] US Department of Health and Human Services (US DHHS). 2004a. Cost of Adopting: Factsheet for Families. Washington, DC: Child Welfare Information Gateway, US DHHS.

[55] US Department of Health and Human Services (US DHHS). 2004b. How many children were adopted in 2000 and 2001? Washington, DC: Child Welfare Information Gateway, US DHHS.

[56] US Department of Health and Human Services (US DHHS). 2008. The AFCARS Report 14: Preliminary FY 2006 Estimates as of January 2008. Washington, DC: Child Welfare Information Gateway, US DHHS. 
[57] Van Voorhis, B. J. 2007. "In Vitro Fertilization," New England Journal of Medicine, 356(4), pp.379-386.

[58] Waldfogel, J. 2004. "Welfare reform and the child welfare system," Children and Youth Services Review, 26, pp.919-939. 
Child Adoption \& Foster Care ${ }^{1}$

Mean

Adoptions

711

0.994

562

1.456

408

0.588

4.728

3.812

12,374

2,380

3.262

6.106

0.466

0.291

214

0.259

366

0.499

7.503

0.009

0.017

1,477

1.743

789

1.723

1,747

2.045

225

0.223

801,357

426,134

0.280

0.721

29.306

0.264

0.170

0.612

0.111

0.535

State Characteristics

Total number of women between ages $35-44^{6}$

Health insurance mandate on infertility treatment ${ }^{7}$

Income per capita $(\$ 1,000)^{2,8}$

Percentage of resident population $(25+)$ with at least a college degree

Percentage black $^{10}$

Female labor force participation rate ${ }^{8}$

Teen birth rate (births to teenage mothers under age 20 as a percent of total births) ${ }^{11}$

Ratio of female resident population between ages 35-44 to those between ages 25-44
St. Dev.

885

0.524

725

0.807

515

0.351

1.428

1.191

19,328

2,841

1.816

3.647

0.048

0.073

532

0.275

343

0.203

10.089

0.006

0.013

2,083

1.778

1,252

2.247

2,447

1.997

407

0.198

920,363

480,674

0.450

0.063

4.828

0.053

0.258

Notes: ${ }^{1}$ AFCARS Adoption and Foster Care Files. Figures reflect unrelated child adoptions unless indicated otherwise. ${ }^{2}$ All figures are expressed in constant 2000 US\$. ${ }^{3}$ North American Council on Adoptable Children, NACAC (N=373). ${ }^{4}$ US Department of State. ${ }^{5} \mathrm{CDC}$ ART Reports. Figures reflect ART cycles performed using fresh non-donor eggs only unless specified otherwise. ${ }^{6}$ US Census Bureau. ${ }^{7}$ Bitler (2007) and Schmidt (2007). ${ }^{8}$ Current Population Surveys. ${ }^{9}$ U.S. Bureau of Economic Analysis. ${ }^{10}$ National Center for Health Statistics. ${ }^{11}$ National Vital Statistics Reports. 
(A) Dependent variable: ART cycles performed (per 1,000 women)

$\begin{array}{rcc}\text { Adoptions (per 1,000 women) } & 0.2058^{*} & -0.2189 * * * \\ & (0.1167) & (0.0728) \\ & 0.1174 & -0.1249 \\ \text { R-squared } & 0.7129 & 0.5988\end{array}$

(B) Dependent variable: ART cycles performed for women $35+$ (per 1,000 women)

$\begin{array}{ccc}\text { Adoptions by adoptive mothers } 35+\text { (per 1,000 women) } & 0.1332 & -0.1951^{* * *} \\ & (0.1078) & (0.0574) \\ \text { R-squared } & 0.1126 & -0.1648 \\ & 0.7508 & 0.6189\end{array}$

(C) Dependent variable: ART cycles performed (per 1,000 women)

$\begin{array}{rcc}\text { Adoptions of children 5+ (per 1,000 women) } & 0.3578^{*} & -0.3044^{* * *} \\ & (0.1956) & (0.0864) \\ & 0.1207 & -0.1027 \\ \text { R-squared } & 0.7152 & 0.5996\end{array}$

$\begin{array}{lcc}\text { Estimation method } & \text { OLS } & \text { FE } \\ \text { Year fixed effects } & \text { Yes } & \text { Yes } \\ \text { State fixed effects } & \text { No } & \text { Yes } \\ \text { Controls } & \text { Yes } & \text { Yes } \\ \text { Observations } & 378 & 378 \\ \text { States } & 49 & 49\end{array}$

Notes: For each regression, we report the estimated coefficient followed by estimated standard error in parentheses and implied elasticity in italics. All specifications include state and year fixed effects as well as the following controls: number of ART clinics (per 1,000 women), indicator for health insurance mandate on infertility treatment, percentage covered by private health insurance, real income per capita, percentage with at least a college degree, percentage black, teen birth rate, female labor force participation rate, and ratio of female resident population between ages 35-44 to those between ages 25-44. Estimates are weighted using total number of women and standard errors are clustered by state. R-squared values in column (2) are calculated without taking the contribution of the state fixed-effects into account. $*, * *, * * *$ indicate statistical significance at $10 \%, 5 \%$, and $1 \%$, respectively. 
Average monthly adoption subsidy (\$100)

Average monthly basic adoption assistance rate for 2-year-olds (\$100)

Number of children in foster care waiting to be adopted (per 1,000 women)

$\%$ girls in foster care waiting to be adopted

$\%$ children 0-4 in foster care waiting to be adopted

\begin{tabular}{|c|c|}
\hline \multicolumn{2}{|c|}{ Adoptions } \\
\hline $\begin{array}{c}\text { IV set I } \\
\text { (1) }\end{array}$ & $\begin{array}{c}\text { IV set II } \\
\text { (2) }\end{array}$ \\
\hline
\end{tabular}

$0.0430 * *$

$(0.0209)$

0.2045

\begin{tabular}{cc}
\multicolumn{2}{c}{ Dependent variable: } \\
\multicolumn{2}{c}{ Adoptive mothers $35+$} \\
\hline IV set I & IV set II \\
(3) & (4) \\
\hline
\end{tabular}

$0.0675^{* *}$

(0.0321)

0.2192
Dependent variable:

Adopted children 5+

IV set I IV set II

(5)

(6)
$0.0358^{* *}$

(0.0138)

0.2881
$0.0353^{*}$

(0.0203)

0.1375

$\begin{array}{cc}0.1929 * * * & 0.1939 * * * \\ (0.0359) & (0.0363) \\ 0.6432 & 0.6349 \\ & \\ 1.6628 * * * & 1.7318 * * * \\ (0.2980) & (0.3394) \\ 0.7921 & 0.8225 \\ & \\ -0.6429 & -0.7865 * \\ (0.3958) & (0.4169) \\ -0.1914 & -0.2324\end{array}$

$0.1644^{* * *}$

$(0.0315)$

0.7022

\begin{abstract}
$0.0619 *$
(0.0328)

0.1650
\end{abstract}

$0.0281^{* *}$

(0.0129)

0.1853

$2.9271 * * *$
$(0.4383)$
0.9542

$$
\begin{gathered}
-1.4089 * * \\
(0.6009) \\
-0.2871
\end{gathered}
$$

$0.1648 * * *$
$(0.0321)$
0.6918

$0.1503^{* * *} *$

(0.0270)

0.8482

$0.1520 * * *$

(0.0273)

0.8424

$3.0680 * * *$
$(0.5017)$
0.9972
$-1.6628 * *$
$(0.6247)$
-0.3363

$1.4305^{* * *}$

(0.2162)

1.1534

$1.5065^{* * *}$

(0.2325)

1.2111

-0.8698 ***
$(0.2655)$
-0.4384

$-0.9980 * * *$

(0.2704)

$-0.4992$

$\begin{array}{cc}378 & 373 \\ 49 & 49 \\ 0.6373 & 0.6363 \\ 19.04 & 17.37 \\ 0.4045 & 0.2816\end{array}$

378
49
0.6507
20.61
0.4417

373
49
0.6521
19.82
0.2760

378

F-statistics for the excluded instruments
Overidentification test of all excluded instruments ( $p$-value for the Hansen J statistic)

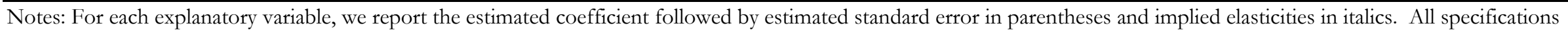

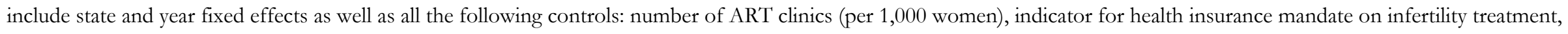

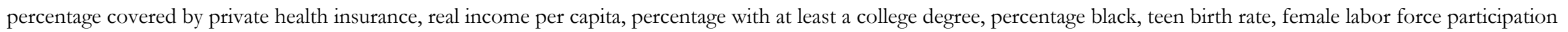
rate, and ratio of female resident population between ages 35-44 to those between ages 25-44. Estimates are weighted using total number of women and standard errors are clustered by state. $*, * *, * * *$ indicate statistical significance at $10 \%, 5 \%$, and $1 \%$, respectively.
} 
(A) Dependent variable: ART cycles performed (per 1,000 women)

$\begin{array}{rcc}\text { Adoptions (per 1,000 women) } & -0.2602^{* * *} & -0.2452^{* * *} \\ & (0.0704) & (0.0776) \\ & -0.1484 & -0.1376 \\ \text { R-squared } & 0.5980 & 0.6059\end{array}$

(B) Dependent variable: ART cycles performed for women 35+ (per 1,000 women)

$\begin{array}{ccc}\text { Adoptions by adoptive mothers } 35+(\text { per } 1,000 \text { women }) & -0.2232^{* * *} & -0.2192^{* * *} \\ & (0.0551) & (0.0587) \\ & -0.1886 & -0.1818 \\ \text { R-squared } & 0.6182 & 0.6226\end{array}$

(C) Dependent variable: ART cycles performed (per 1,000 women)

$\begin{array}{ccc}\text { Adoptions of children } 5+(\text { per 1,000 women) } & -0.3337 * * * & -0.3135^{* * *} \\ & (0.0869) & (0.0965) \\ & -0.1125 & -0.1040 \\ \text { R-squared } & 0.5994 & 0.6069\end{array}$

Estimation method

Observations

States
FE 2SLS (IV set I)

378

49
FE 2SLS (IV set II)

373

49

Notes: For each regression, we report the estimated coefficient followed by estimated standard error in parentheses and implied elasticity in italics. All specifications include state and year fixed effects as well as all the following controls: number of ART clinics (per 1,000 women), indicator for health insurance mandate on infertility treatment, percentage covered by private health insurance, real income per capita, percentage with at least a college degree, percentage black, teen birth rate, female labor force participation rate, and ratio of female resident population between ages 35-44 to those between ages 25-44. IV set I and II are presented in Table 3 . $\mathrm{R}$-squared values are calculated without taking the contribution of the state. Estimates are weighted using total number of women and standard errors are clustered by state. $*, * *, * * *$ indicate statistical significance at $10 \%, 5 \%$, and $1 \%$, respectively. 
(A) Dependent variable: ART cycles performed (per 1,000 women)

$$
\begin{array}{rc}
\text { Unrelated adoptions (per 1,000 women) } & -0.2188^{* * *} \\
& (0.0750) \\
& -0.1248 \\
\text { Related adoptions (per 1,000 women) } & -0.0015 \\
& (0.2502) \\
& -0.0002 \\
\text { R-squared } & 0.5986 \\
\text { Observations } & 378 \\
\text { States } & 49
\end{array}
$$

(B) Dependent variable: ART cycles performed (per 1,000 women)

Unrelated foster care adoptions (per 1,000 women)

$-0.2178^{* * *}$

$(0.0732)$

$-0.1243$

International adoptions (per 1,000 women)

$-0.7611 * *$

(0.3707)

$-0.2180$

R-squared

0.6074

Observations

378

States

(C) Dependent variable: ART cycles performed using fresh \& frozen non-donor eggs (per 1,000 women)

$\begin{array}{rc}\text { Adoptions (per 1,000 women) } & -0.2657 * * * \\ & (0.0837) \\ & -0.1291 \\ \text { R-squared } & 0.6387 \\ \text { Observations } & 378 \\ \text { States } & 49\end{array}$

(D) Dependent variable: ART cycles performed using fresh \& frozen donor eggs (per 1,000 women)

$\begin{array}{rc}\text { Adoptions (per 1,000 women) } & -0.0217 \\ & (0.0276) \\ & -0.0971 \\ & 0.5413 \\ \text { R-squared } & 378 \\ \text { Observations } & 49 \\ \text { States } & \end{array}$

Notes: For each regression, we report the estimated coefficient followed by estimated standard error in parentheses and implied elasticity in italics. All specifications include state and year fixed effects as well as the following controls: number of ART clinics (per 1,000 women), indicator for health insurance mandate on infertility treatment, percentage covered by private health insurance, real income per capita, percentage with at least a college degree, percentage black, teen birth rate, female labor force participation rate, and ratio of female resident population between ages 35-44 to those between ages 25-44. Estimates are weighted using total number of women and standard errors are clustered by state. R-squared values are calculated without taking the contribution of the state fixed-effects into account. *, **, *** indicate statistical significance at $10 \%, 5 \%$, and $1 \%$, respectively. 